\title{
POLITENESS IN COMPLIMENT RESPONSES OF MALAYSIA CHINESE UNDERGRADUATES
}

\author{
Yingqi Wu and Baljit Kaur \\ University of Malaya
}

\begin{abstract}
Politeness appears to be a prevalent concept in human interaction, and to date, many models of politeness have been put forward in the literature. This study analyses a corpus of compliment responses (CRs) in Malaysian Chinese undergraduates according to the Politeness Principles of Gu (1992) with a view to examine the politeness in responding to compliments. The data in the present study were collected from 30 undergraduates in a local university through role-play scenarios, with a focus on the variables of topic (appearance, character, ability and possession), social distance and social status. The findings of the study show that Malaysian Chinese undergraduates chose various politeness strategies in their CRs among different circumstances. Malaysian Chinese undergraduates' politeness is greatly influenced by collectivism in Chinese culture so they are more others-oriented. Therefore, they are greatly governed by the Accordance Maxim in CRs by using Acceptance, especially Appreciation strategies. With the assimilation of English, Malaysian Chinese undergraduates are also likely to keep the Refinement Maxim in which indirect responses such as giggling/smiling are frequently used to show great politeness. Nevertheless, the preference of politeness strategies may vary between nowadays Malaysian Chinese and other Chinese generations as there is less preference of Self-denigration Maxim among them in communication.
\end{abstract}

KEYWORDS: COMPLIMENT-RESPONSE STRATEGIES, POLITENESS, MALAYSIAN CHINESE UNDERGRADUATES, SPEECH ACTS, FACE

\section{Introduction}

Politeness appears to be a social-cultural phenomenon, which can be generally defined as showing consideration to others in human interactions ( $\mathrm{Yu}, 2003$ ). Politeness is a construct that has been appealed to widely in explaining language use and has been conceptualized in a number of different ways as verbal and non-verbal behaviors that maintain harmonious relations and face (Brown \& Levinson, 1987; Leech 1983; Ruhi, 2006). Investigations have been carried out aiming to pursuit a better understanding of politeness phenomenon in a variety of cultures. The purpose of the studies of politeness is to reflect or realize the social or interpersonal functions of various languages by reducing the potential conflict and miscommunication in human interaction.

Among various speech acts studied to date, studies on compliment responses (CRs) are central to furthering the understanding of politeness since it is an act that responds to display of genuine or routine concern for others (Ruhi, 2006). Previous studies on speech acts reveal that majority of researches investigated cross-cultural and cross-linguistic similarities and distinctions in preferred responses strategies (Barnlund \& Araki 1985; Liu 1995). There are only a few studies conducted on the compliment responses (CRs) that evaluate various aspects of the face-saving and the politeness models and devote attention to theoretical implications (Chen 1993; Spencer-Oatey et al., 2000; Yu 2003). 


\section{POLITENESS IN COMPLIMENT RESPONSES OF MALAYSIA CHINESE UNDERGRADUATES}

This study investigates whether Malaysian Chinese use face-saving strategies when responding to compliments in different communicative situations and to identify the main politeness strategies used to reduce face threat in responding to compliments.

\section{Literature Review}

\section{Western Concepts of Face and Politeness}

The basic notion of Western politeness theory is 'face' that is defined as 'the positive social value a person effectively claims for himself by the line others assume he has taken during a particular contact" by Goffman (1967). Thus, face is defined as "the public self-image that every member wants to claim for himself" and "something that is emotionally invested, and that can be lost, maintained, or enhanced, and must be constantly attended to in interaction" (Brown and Levinson, 1987:61). Brown and Levinson (1987) further claimed that "face" has two aspects: positive face, which is the desire to be liked by others; negative face, which is the desire to act unimpeded by other people. Nevertheless, the behaviors of satisfying others' personal desires or wants may lead to the acts that inevitably threaten both faces of the interactants. Thereby, Brown and Levinson (1987) defined these acts as 'face-threatening acts (FTAs)'.

Geoffrey N. Leech (1983:104) considered politeness as a form of behavior that aims to achieve the establishment and maintenance of comity, which is the ability of participants to engage in interaction in an atmosphere of relative harmony. He established six maxims to describe politeness which are termed as Politeness Principle which is shown in the following:

1) Tact Maxim:

Minimize cost and maximize benefit to others

2) Generosity Maxim:

Minimize benefit and maximize cost to self

3) Approbation Maxim:

Minimize dispraise and maximize praise of other

4) Modesty Maxim:

Minimize praise and maximize dispraise of self

5) Agreement Maxim:

Minimize disagreement and maximize agreement between self and others

6) Sympathy Maxim:

Minimize antipathy and maximize sympathy between self and others

\section{Chinese Concepts of Face and Politeness}

Criticisms of Brown and Levinson's face framework and Leech's maxim model have been restricted more to the difficulty of working out which maxims apply for a given utterance (Fraser, 1990). Gu Yueguo (1990) criticized the unsuitability of Brown and Levinson's face framework for Chinese politeness. Limao (礼貌) (morphemically means 'polite appearance') is the equivalent Chinese expression to English word 'politeness'. There are four essential notions in the Chinese Limao: respectfulness, modesty, attitudinal warmth and refinement (Gu, 1990). Hu (1994) claimed that there are two aspects of face in Chinese culture. The first is mianzi (面子) that refers to "prestige or reputation" which can be either achieved by enrolling in community or being ascribed by other community fellows; another one is lian (脸) that refers to "the respect of the group for a member with a good moral standard" (Yu, 2003). 


\section{POLITENESS IN COMPLIMENT RESPONSES OF MALAYSIA CHINESE UNDERGRADUATES}

Comparing the faces in Western and Chinese cultural backgrounds, it is noticeable that the face of Brown \& Levinson (1987) is defined as an individualistic and self-oriented image, on the contrary, Chinese face emphasizes communality and interpersonality (Yu, 2003). Furthermore, the Chinese concept of negative face differs from the one of Brown and Levinson. In Chinese community, speech acts such as offering, inviting and promising, ordinarily speaking, are not regarded as impeding hearer's freedom, let alone threatening hearer's negative face. Second, beyond the sole instrumental function of Brown and Levinson's face model, politeness, in Chinese social setting, also performs its normative functions $(\mathrm{Gu}, 1990)$.

$\mathrm{Gu}$ (1992) defined culture as a set of maxims which were used to explain behaviors. Therefore, $\mathrm{Gu}$ (1992) adapted Leech's Politeness Principle to construct politeness maxims accounting for the moralization of Chinese value and culture.

1) The Self-denigration Maxim:

The maxim consists of two clauses or submaxims (a) denigrate self and (b) elevate other. This maxim absorbs the notions of respectfulness and modesty. The Self-denigration Maxim is based on the respectfulness and modesty of Chinese Limao (礼貌). Rather than surnames, Chinese interlocutors obey the maxim of denigration in most politeness-sensitive aspects such as professions, belongings, reading, etc. $\mathrm{Gu}$ (1992) also pointed out a new phenomenon that since the foundation of People's Republic of China, new views and values have changed and have replaced some of the traditional ones. Nevertheless, a set of neutral terms appear and are widely used by people.

2) The Address Maxim:

The maxim reads: address your interlocutor with an appropriate address term. This maxim is based on the notions of respectfulness and attitudinal warmth. There are two aspects involved in naming addressees: (a) speaker's recognition of hearer as a social being in his/her specific social status or role; (b) speaker's definition of the social relation between speakers and hearers. In Chinese culture, the complex use of address reflects a kind of social relationship between people, a failure to name others appropriately may result in offense. Gu $(1990,1992)$ divided the system of addressing into two categories: unitary and multiple addressing terms. The former one refers to the terms that can be singly used such as one's profession, and the latter one refers to the terms that are composed of two or more sub-addressing terms like "old /little+LN" and "LN+old". However, more pragmatics elements are needed to be taken into consideration in order to address appropriately, for instance, kin or non-kin, male or female, etc.

3) The Refinement Maxim:

The maxim refers to self's behavior to other which meets certain standards. With regard to language use, it means the use of refined language and a ban on foul language. The use of euphemisms and indirectness is also covered in this maxim. The Refinement Maxim refers to the use of refined words and avoid obscene expressions as well as use more euphemisms and less straightforward expressions. For instance, A wants to taste something like a cake belonging to B, A's expression "The cake looks very delicious" would be regarded as a refined utterance rather than the direct request "I want to eat this cake".

4) The Accordance Maxim:

The maxim refers to the efforts made by both interlocutors to maximize agreement and harmony and minimize disagreement. The Accordance Maxim is highly related to Chinese face (as mentioned: lian; mianzi). As shown in ShangTong section in MoZi ( 《墨子. 尚同》), the central idea of agreement in Chinese is to agree with addressees as much as possible in order to satisfy the addressees' 


\section{POLITENESS IN COMPLIMENT RESPONSES OF MALAYSIA CHINESE UNDERGRADUATES}

psychological desires thus to build a harmonious relationship with them. In Chinese daily interactions, if someone is really holding a different opinion with the interlocutor, he/she is more likely to compliment firstly and then denigrate him/herself with expression of his/her common opinion, and lastly points out the addressees' insufficiencies and drawbacks. In this way, the faces of both speakers will be kept.

5) The Virtues-Words-Deeds Maxim:

This maxim refers to minimizing cost and maximizing benefit to other at the motivational level (being virtuous), and maximizing benefit received and minimizing cost to self at the conversational level (being a nobleman). The speech and virtue are significant elements in Confucianism School, China (Huang, 2012). According to Confucianism School, being polite, speakers should consider the virtue, words and deeds as a unity, and always pay attention to the cost and benefit related to self and the others.

\section{Politeness with CRs}

Starting with Holmes (1988), theories of politeness have been employed to account for the studies of CRs in different social contexts. Holmes (1988) used politeness theory of Brown \& Levinson for New Zealand data, Sharifian (2005) posited an approach of cultural schema to account for his Persian data while Thevendiraraj (2006) used Leech's Politeness Maxims for her Malaysian Tamil data.

Chen (1993) stated that Brown \& Levinson's politeness theory is just suitable for the English data but not for Chinese data, whereas Gu's (1990) concept of modesty can just explain why Chinese rejected compliments dramatically. With overall consideration, Leech's (1983) politeness maxims especially the Agreement Maxim and Modesty Maxim can explain the CRs of English and Chinese data respectively. Countering to the findings of Mainland Chinese in Chen's (1993) study, Chen, S. H (2003) investigated compliment responses of Chinese speakers in Taiwan and found that the most frequently applied CRs strategy was acceptance which indicated that Taiwanese were mostly motivated by Leech's Agreement Maxim. Denying other's praise is an appropriate behavior in China, therefore for Chinese, acceptance runs the risk of showing off or violating the modesty and the value of self-denigration has imposed on the Chinese community to avoid explicit acceptance with the compliment (Zhang, 2005). These cultural values account for the study of Cheng (2009) which shows Chinese use Implicit Acceptance more frequently than Explicit Acceptance to respond to compliments. And another feature shared in the previous studies is that the focus of denial is on the complimentee $\mathrm{him} /$ herself, never on the compliments (Cheng, 2009).

This study is an attempt to shed light on politeness in compliment responses generated by Malaysian Chinese undergraduates with the purpose of studying the major politeness strategies as well as possible similarity or difference with past studies.

\section{Methodology}

\section{Participants}

The data of this research consists of 240 compliment responses from 30 Malaysian Chinese undergraduates who were selected from a local university. All the participants were introduced by friends of the researcher. Previous studies proved that a sample size of 30 participants is considered sufficient for the study of speech acts through Discourse Completion Task (DCT) (Kasper \& Dahl, 1991; Thevendiraraj, 2006). 


\section{POLITENESS IN COMPLIMENT RESPONSES OF MALAYSIA CHINESE UNDERGRADUATES}

\section{Instruments}

Table 1: Situations of CRs related to the social status and social distance

\begin{tabular}{cccc}
\hline Situation & Subject & Social Power & Social Distance \\
\hline $1 \mathrm{a}$ & Appearance & $>$ & + \\
$1 \mathrm{~b}$ & Appearance & $=$ & - \\
$2 \mathrm{a}$ & Character & $>$ & - \\
$2 \mathrm{~b}$ & Character & $=$ & + \\
$3 \mathrm{a}$ & Ability & $>$ & + \\
$3 \mathrm{~b}$ & Ability & $=$ & - \\
$4 \mathrm{a}$ & Possession & $>$ & - \\
$4 \mathrm{~b}$ & Possession & $=$ & + \\
\hline
\end{tabular}

The data in this study was mainly collected through role play scenarios (Appendix A) which were adapted from DCT of Tang and Zhang (2009). Role plays allow the research to elicit more real-life data (Shahsavari et al., 2014). There are four situations with compliments on appearance (situation 1), character (situation 2), ability (situation 3) and possession (situation 4) in the present role play scenarios (see Table 1). In each situation, there are 2 sub-settings (a and b) that are under the same social setting, however, involve two different social variables: social status (high $>/$ equal $=$ ) and social distance (familiar $+/$ unfamiliar -). Questionnaire was another instrument employed in this study to gather a large and useful corpus of data (Tran, 2006). There are five questions (Appendix B) replicated from Thevendiraraj (2006) due to the similar function of acquiring deep insights of participants regarding their responses to the compliments.

\section{Procedure}

Some Malaysian Chinese undergraduates in a local university were invited to join the study. Participants were given a clear description of the study. After that the consent forms were signed by the participants. Each participant was required to read the situation typed on a card first then two complimenters gave the compliments on sub-situations in sequence. The participant just responded orally to the compliments. The whole process of the role play was audio recorded. After the role play, participants answered the given questionnaires individually by recalling their performance in the role play and everyday life. All the data of compliment responses in the recordings of the role plays were transcribed based on the transcription model of Thevendiraraj (2006) who adapted Jefferson's (1972) transcription model to investigate CRs of Malaysian Tamil community.

\section{Data analysis}

In order to identify various CRs strategies, the CRs categorization of Cheng (2011) was applied to account for CRs data. There are 11 micro levels which are further subsumed within three macro categories (shown in Table 2). In accounting for the face-saving strategies in CRs, Gu's (1992) Politeness Principles framework (see Table 3) was used. The questionnaire data was analysed 


\section{POLITENESS IN COMPLIMENT RESPONSES OF MALAYSIA CHINESE UNDERGRADUATES}

descriptively.

Table 2: CRs categories of Cheng (2011)

\begin{tabular}{|c|c|c|}
\hline Macro level & Micro level & Example \\
\hline \multirow{6}{*}{ Acceptance } & Appreciation & Thank you very much. \\
\hline & Agreeing & Yeah, I really like it. \\
\hline & Downgrading & It's nothing. \\
\hline & Qualifying & I love doing it. \\
\hline & Returning & Yours is nice too. \\
\hline & Non-idiomatic & I am very happy. \\
\hline \multirow{6}{*}{ Evasion } & Credit-shifting & My pleasure.. \\
\hline & Commenting & I like red color. \\
\hline & Reassuring & Are you kidding? \\
\hline & Offering & You can use mine if you like it. \\
\hline & \multirow[t]{2}{*}{ Ignoring/Giggling } & $\begin{array}{l}\text { No response } \\
\text { Shifting to another topic }\end{array}$ \\
\hline & & Giggling/Smiling \\
\hline Combination & \multicolumn{2}{|c|}{$\begin{array}{l}\text { Acceptance }+ \text { Evasion } \\
\text { E.g. Appreciation }+ \text { Credit-shifting } \\
\text { E.g. Thank you so much. It is a gift from my brother. }\end{array}$} \\
\hline
\end{tabular}

Table 3: Politeness Principles of Gu (1992)

Maxim

(1) The Self'-denigration Maxim

(2) The Address Maxim

(3) The Refinement Maxim

(4) The Accordance Maxim

(5) The Virtues-Words-Deeds Maxim

\section{Explanation}

(a) denigrate self

(b) elevate others

Address the interlocutor with an appropriate address term

(a) the use of refined words and avoid obscene expressions

(b) the use more euphemisms and less straightforward expressions

(a) maximize agreement and harmony

(b) minimize disagreement.

(a) minimizing cost and maximizing benefit to other at the motivational level

(b) maximizing benefit received and minimizing cost to self at the conversational level 


\section{POLITENESS IN COMPLIMENT RESPONSES OF MALAYSIA CHINESE UNDERGRADUATES}

\section{Results}

\section{Politeness Strategies in Generic CRs}

According to the analyses of questionnaires, 25 out of 30 participants stated that they would feel happy, excited or pleased by receiving compliments; the other 5 participants admitted that sometimes they might feel embarrassed if they were praised. Therefore, on the whole, Malaysian Chinese undergraduates did not regard compliments as face-threatening acts. Nevertheless, in responding to compliments, 28 participants said that they think about politeness as it is an important part in communication.

Based on the five politeness maxims of Gu (1992) (Table 3), the macro strategy of Acceptance belongs to the Accordance Maxim which states that the speakers try to maximize agreement and harmony with the interlocutor. There are 99 out of 240 responses showing explicit acceptance, thus $41 \%$ of total is abided by the Accordance Maxim. The responses of Acceptance like 'Thank you! I like it too' can be considered showing agreement because there is no unambiguously attributable intention with which both interactants concur or accept the compliments. Likewise, it is also shown that the participants avoided violating the Accordance Maxim as shown by the rare use of Rejection which apparently turns down the compliments. Most of the participants mentioned that they were growing up in Chinese families where they were taught to treat others friendly. As a minority in Malaysia, explained by some participants, Malaysian Chinese need to face people from other ethnic groups who may have different religions, languages and cultures, therefore they need to build up a harmonious relationship with everyone around them. In order to avoid conflicts in daily communication, generally speaking, they tend to agree with others. As a consequence, Malaysian Chinese in this study tended to accept the compliments from others to maintain harmony in the interaction.

Table 4: Compliment responses at macro level

\begin{tabular}{ccc}
\hline Macro Type of CRs & Number & Percentage \\
\hline Acceptance & 99 & $41 \%$ \\
Combination & 89 & $37.5 \%$ \\
Evasion & 51 & $21 \%$ \\
Rejection & 1 & $0.5 \%$ \\
TOTAL & 240 & $100 \%$ \\
\hline
\end{tabular}

There are 51 (21\%) CRs classified into Evasion which refers to the indirect acceptance to the compliments so that reveal the contents of the Refinement Maxim. As explained by Gu (1992), speakers need to use refined words and avoid obscene words; or use more euphemisms and less straight-forward expressions in utterances. All the responses collected are verbally spoken in clear and simple English rather than refined words and rarely-understood expressions when responding to compliments. The participants also meant to agree with the compliments, however, they did not express it straightway but less-straightforward. Compared to the macro-level responses of Acceptance and Evasion, 89 pieces of responses (37.5\%) are Combination, in which the $98 \%$ is the Combination 


\section{POLITENESS IN COMPLIMENT RESPONSES OF MALAYSIA CHINESE UNDERGRADUATES}

of Acceptance and Evasion, while only $2 \%$ of Combination strategies involves Rejection. Therefore, the majority of respondents were governed by the Accordance Maxim and the Refinement Maxim in responding to compliments. In order to account for the politeness in CRs of Malaysian Chinese undergraduates in details, further analysis was carried out on different maxims in sequence.

\section{The Self-denigration Maxim}

The most typical feature of Chinese politeness is to respect others by being self-effacing, in which the central idea is that one should denigrate self and elevate others (Gu, 1990, 1992). In Chinese culture, when people tend to make negative answer or self-denigration, modesty has been greatly shown (Zhang, 2005). As the researcher has analyzed the CRs framework of Cheng (2011), Downgrading (e.g., It's nothing / It is not so good) and Returning (e.g., Wow you too) manifest the Self-denigration Maxim.

Out of 397 CRs strategies (Table 5), there are 35 strategies (9\%) in four situations that show the Self-denigration Maxim. It obviously indicates that participants did not obey this maxim much in their CRs. Respondents mainly used Downgrading strategies (10 out of 35) to scale down the praise thus denigrate the self. In employing the strategies of Returning (25 out of 35), the respondents seemed to imply that they accepted the positive valuation firstly then elevated the positive aspects of the compliments giver. In viewing of the Self-denigration Maxim, Malaysian Chinese undergraduates inclined to elevate others rather than denigrating themselves.

Table 5: Generic CRs at micro level

\begin{tabular}{lcc}
\hline CRs Type & Number & Percentage (\%) \\
\hline Acceptance & & \\
Appreciation & 163 & 41 \\
Returning & 25 & 6 \\
Qualifying & 16 & 4 \\
Agreeing & 16 & 4 \\
Downgrading & 10 & 3 \\
Total & 230 & 58 \\
& & \\
Evasion & & 16 \\
Giggling/Smiling & 63 & 10 \\
Commenting & 40 & 8.6 \\
Credit-shifting & 34 & 3.5 \\
Reassuring & 14 & 2 \\
Topic-shifting & 8 & 1.2 \\
Offering & 5 & 41.3 \\
Total & 164 & 0.8 \\
& & 100 \\
Rejection & 3 & \\
TOTAL & 397 & \\
\hline
\end{tabular}

In situation 1 with compliments on appearance (see Table 6), 16 CRs strategies (Downgrading and Returning) have been identified as the Self-denigration maxim. It can be seen that the participants preferred not to denigrate their out-looking; on the contrary, they may elevate the appearance of the 


\section{POLITENESS IN COMPLIMENT RESPONSES OF MALAYSIA CHINESE UNDERGRADUATES}

interlocutors. Based on the deep comparison between two sub-situations, the respondents would like to elevate more on someone unfamiliar with equal social status. With the compliments on character in situation 2 (see Table 7), there were 8 CRs of Downgrading in which 5 in situation $2 \mathrm{a}$ and 3 in situation $2 \mathrm{~b}$. The only one Returning strategy found in situation $2 \mathrm{~b}$ suggests that the participants tended not to keep this maxim much in terms of CRs on character. For the compliment topic of ability (see Table 8), surprisingly, the participants have never denigrated themselves. Similarly, they did not return the compliments to familiar lecturer, whereas, $8 \mathrm{CRs}$ strategies show the elevation of unfamiliar classmate's ability. Unlikely in situation 4 (see Table 9) where the compliments are paid on possession, the Returning has not been used which indicates no elevation at all; only one response of Downgrading found in each sub-situation. In consequence, the respondents showed a less preference of the Self-denigration Maxim as showing modesty in responding to compliments, especially on personal possession. It is sustained by the questionnaires in which only 4 participants out of 30 mentioned that they would concern modesty in their CRs.

Table 6: Micro-level CRs for appearance

\begin{tabular}{ccccccc}
\hline CRs Strategy & \multicolumn{2}{c}{ Situation 1a } & \multicolumn{2}{c}{ Situation 1b } & \multicolumn{2}{c}{ Situation 1 } \\
\cline { 2 - 7 } & Number & Percent & Number & Percent & Number & Percent \\
\hline Appreciation & 31 & $60 \%$ & 24 & $43.6 \%$ & 55 & $51 \%$ \\
Agreeing & 0 & 0 & 0 & 0 & 0 & 0 \\
Downgrading & 0 & 0 & 0 & 0 & 0 & 0 \\
Qualifying & 2 & $4 \%$ & 0 & 0 & 2 & $2 \%$ \\
Returning & 4 & $8 \%$ & 12 & $21.8 \%$ & 16 & $15 \%$ \\
Credit-shifting & 0 & 0 & 0 & 0 & 0 & 0 \\
Commenting & 0 & 0 & 0 & 0 & 0 & 0 \\
Reassuring & 2 & $4 \%$ & 4 & $7.3 \%$ & 6 & $6 \%$ \\
Offering & 0 & 0 & 0 & 0 & 0 & 0 \\
Giggling/Smiling & 11 & $22 \%$ & 9 & $16.4 \%$ & 20 & $19 \%$ \\
Topic-shifting & 1 & $2 \%$ & 5 & $9.1 \%$ & 6 & $6 \%$ \\
Rejection & 0 & 0 & 1 & $1.8 \%$ & 1 & $1 \%$ \\
TOTAL & 51 & $100 \%$ & 55 & $100 \%$ & 106 & $100 \%$ \\
\hline
\end{tabular}

Table 7: Micro-level CRs for character

\begin{tabular}{ccccccc}
\hline CRs Strategy & \multicolumn{2}{c}{ Situation 2a } & \multicolumn{2}{c}{ Situation 2b } & \multicolumn{2}{c}{ Situation 2 } \\
\cline { 2 - 6 } & Number & Percent & Number & Percent & Number & Percent \\
\hline Appreciation & 7 & $15.7 \%$ & 19 & $43.1 \%$ & 26 & $29.3 \%$ \\
Agreeing & 0 & 0 & 1 & $2.3 \%$ & 1 & $1.1 \%$ \\
Downgrading & 5 & $11.1 \%$ & 3 & $6.8 \%$ & 8 & $9 \%$
\end{tabular}



UNDERGRADUATES

\begin{tabular}{ccccccc} 
Qualifying & 1 & $2.2 \%$ & 1 & $2.3 \%$ & 2 & $2.2 \%$ \\
Returning & 0 & 0 & 1 & $2.3 \%$ & 1 & $1.1 \%$ \\
Credit-shifting & 25 & $55.6 \%$ & 5 & $11.4 \%$ & 30 & $33.7 \%$ \\
Commenting & 2 & $4.4 \%$ & 0 & 0 & 2 & $2.2 \%$ \\
Reassuring & 1 & $2.2 \%$ & 1 & $2.3 \%$ & 2 & $2.2 \%$ \\
Offering & 1 & $2.2 \%$ & 0 & 0 & 1 & $1.1 \%$ \\
Giggling/Smiling & 2 & $4.4 \%$ & 13 & $29.5 \%$ & 15 & $17 \%$ \\
Topic-shifting & 1 & $2.2 \%$ & 0 & 0 & 1 & $1.1 \%$ \\
Rejection & 0 & 0 & 0 & 0 & 0 & 0 \\
TOTAL & 45 & $100 \%$ & 44 & $100 \%$ & 89 & $100 \%$ \\
\hline
\end{tabular}

Table 8: Micro-level CRs for ability

\begin{tabular}{ccccccc}
\hline CRs Strategy & \multicolumn{2}{c}{ Situation 3a } & \multicolumn{2}{c}{ Situation 3b } & \multicolumn{2}{c}{ Situation 3 } \\
\cline { 2 - 7 } & Number & Percent & Number & Percent & Number & Percent \\
\hline Appreciation & 30 & $68.2 \%$ & 19 & $40.4 \%$ & 49 & $53.8 \%$ \\
Agreeing & 0 & 0 & 0 & 0 & 0 & 0 \\
Downgrading & 0 & 0 & 0 & 0 & 0 & 0 \\
Qualifying & 8 & $18.2 \%$ & 0 & 0 & 8 & $8.8 \%$ \\
Returning & 0 & 0 & 8 & $17.1 \%$ & 8 & $8.8 \%$ \\
Credit-shifting & 2 & $4.5 \%$ & 0 & 0 & 2 & $2.2 \%$ \\
Commenting & 0 & 0 & 1 & $2.1 \%$ & 1 & $1.1 \%$ \\
Reassuring & 1 & $2.3 \%$ & 0 & 0 & 1 & $1.1 \%$ \\
Offering & 0 & 0 & 1 & $2.1 \%$ & 1 & $1.1 \%$ \\
Giggling/Smiling & 3 & $6.8 \%$ & 17 & $36.2 \%$ & 20 & $22.0 \%$ \\
Topic-shifting & 0 & 0 & 1 & $2.1 \%$ & 1 & $1.1 \%$ \\
Rejection & 0 & 0 & 0 & 0 & 0 & 0 \\
TOTAL & 44 & $100 \%$ & 47 & $100 \%$ & 91 & $100 \%$ \\
\hline
\end{tabular}

Table 9: Micro-level CRs for possession

\begin{tabular}{ccccccc}
\hline CRs Strategy & \multicolumn{2}{c}{ Situation 4a } & \multicolumn{2}{c}{ Situation 4b } & \multicolumn{2}{c}{ Situation 4 } \\
\cline { 2 - 7 } & Number & Percent & Number & Percent & Number & Percent \\
\hline Appreciation & 20 & $45.7 \%$ & 13 & $23.6 \%$ & 33 & $29.7 \%$ \\
Agreeing & 8 & $14.2 \%$ & 7 & $12.8 \%$ & 15 & $13.5 \%$ \\
Downgrading & 1 & $1.8 \%$ & 1 & $1.8 \%$ & 2 & $1.8 \%$ \\
Qualifying & 0 & 0 & 4 & $7.3 \%$ & 4 & $3.6 \%$ \\
\hline
\end{tabular}




\section{POLITENESS IN COMPLIMENT RESPONSES OF MALAYSIA CHINESE UNDERGRADUATES}

\begin{tabular}{ccccccc}
\hline Returning & 0 & 0 & 0 & 0 & 0 & 0 \\
Credit-shifting & 2 & $3.6 \%$ & 0 & 0 & 2 & $1.8 \%$ \\
Commenting & 20 & $35.7 \%$ & 17 & $30.9 \%$ & 37 & $33.4 \%$ \\
Reassuring & 0 & 0 & 5 & $9.1 \%$ & 5 & $4.5 \%$ \\
Offering & 1 & $1.8 \%$ & 2 & $3.6 \%$ & 3 & $2.7 \%$ \\
Giggling/Smiling & 3 & $5.4 \%$ & 5 & $9.1 \%$ & 8 & $7.2 \%$ \\
Topic-shifting & 0 & 0 & 0 & 0 & 0 & 0 \\
Rejection & 1 & $1.8 \%$ & 1 & $1.8 \%$ & 2 & $1.8 \%$ \\
TOTAL & 56 & $100 \%$ & 55 & $100 \%$ & 111 & $100 \%$ \\
\hline
\end{tabular}

\section{The Address Maxim}

The core idea of this maxim is that there shall be propriety and righteousness between the superior and the inferior. In this study, not many address terms have been used in responding to compliments. There are 15 responses including address forms, the majority (12 out of 15) of which appeared in situation 3a (e.g., teacher / sir / lecturer / doctor) where the communication is processing with a familiar lecturer in class.

As demonstrated by the respondents, they were accustomed to addressing someone with higher status in some formal occasions like in class or meeting; however, they might overlook the importance of naming others in casual conditions like a party in situation 1 . In addition to situation $3 \mathrm{a}$, another 3 addressing terms were found in situation 1a and $2 \mathrm{a}$, in which the interlocutors are lecturers and an office staff. Therefore, this kind of phenomenon may imply that the participants are accustomed to addressing someone familiar with higher social status, especially in academic circles. According to the semantic analysis of the addressing terms, all participants used 'teacher, lecturer, sir and Doctor' which is defined as unitary addressing form to name the complimenters ( $\mathrm{Gu}, 1992)$. Based on the analyses of the data transcription and questionnaires, to address others appropriately, participants in this study considered a few pragmatic elements such as professionally prestigious or non-prestigious, familiar and unfamiliar, on a formal or informal occasion.

\section{The Refinement Maxim}

To be refined means to use refined words and avoid obscene expressions, and to use more euphemisms and less straight-forward words. First, there are no refined words used by respondents in their responses, instead, all the English expressions or words are simple and very daily-used that can be understood easily (e.g., Giggle / You are welcome / You can buy too. This is really a good phone).

Meanwhile rude or obscene words have not been found in their CRs. And all the English expressions are viewed as neutrally polite. According to the analyses of questionnaires, the participants violated using refined expressions due to the language differences in vocabulary and expressions as well as the model of thinking between Chinese and English. First of all, some participants admitted that most Chinese expressions such as idioms or polite formulas have no responding expressions in English due to their limitation of English proficiency; therefore, they have to choose easy responses instead of refined ways. Another reason is that they speak English as a second language in daily lives, when they use English as the medium of communication, they try to follow English thinking rather than transferring Chinese culture into it, hence, they try to imitate the briefness of native English speakers. 


\section{POLITENESS IN COMPLIMENT RESPONSES OF MALAYSIA CHINESE UNDERGRADUATES}

As shown in Table 5, 164 (41.3\%) responses are clarified as Evasion which refers to use more euphemisms and less straight-forward words. In the four situations shown by Table 5-8, the applications of Evasion have shown no significant distinction among topics on appearance (55\%), character (57.2\%) and possession (49.9\%), nevertheless, in situation 3 with compliments on ability, there is a less popularity with Evasion (28.2\%). According to the further analysis on subjects, when respondents were facing unfamiliar speakers in higher status in situation 2 a (shown in Table 6), they employed more strategies of Evasion (69.2\%) which accounts that they preferred indirect responses to avoid face-threatening acts in terms of compliments on character. In responding to compliments on ability (see Table 8) with familiar speakers in higher status, they used the least Evasion (13.6\%) that reveals the Refinement Maxim. Out of 164 strategies of Evasion (see Table 5), Giggling/Smiling has been used mostly by taking up 38\% of total Evasion. According to the results found through the questionnaires, 16 out of 30 participants believed that Giggling/Smiling is non-verbal but polite expressions can be used as the strategy for responding to compliments because it makes people neither feel over-humble nor conceited to reject or accept the compliments directly. Therefore, Giggling/Smiling, despite being non-verbal, can be an important strategy for participants as it carries emotional and meaningful message whose function is same as refined verbal expressions.

\section{The Accordance Maxim}

The kernel of this maxim is to be in agreement with others as much as possible so as to satisfy the other's psychological desires and to keep a harmonious relationship among each other. Based on that, strategies of Appreciation (e.g., Thank you / Thanks / Yeah), Agreeing (e.g., Yeah, I think so / Yes) and Qualifying (e.g., I hope I manage to help you to carry out these books) can be considered as following the rule of agreement; on the other hand, CRs of Rejection are viewed as violation of it.

In total, there are 195 CRs of Appreciation, Agreeing and Qualifying (see Table 5) in the study, which take a large proportion of $49 \%$ of all CRs. Among the three strategies, Appreciation is the most preferred one with $163(83.6 \%)$ out of 191 ; another two are used by $8.2 \%$ respectively. The majority of participants applied Appreciation as the most favorable response. As questionnaires showed, most participants believed that 'Thank you' should be their immediate response to compliments because it will be rude if not to accept the compliments, besides, half of the participants pointed out that showing their gratefulness is their responsibility if others are kind to pay compliments. Specific to the situations that are shown in Table 6-9, Malaysian Chinese participants kept the most Accordance Maxim on topics of ability (62.6\%) and appearance (53\%), however, the least with character $(32.6 \%)$. Therefore, this result justifies that Malaysian Chinese undergraduates preferred to show politeness by the Accordance Maxim with the compliments on personal ability, reversely, they did not pay much attention to this maxim when compliments were paid to personality.

Comparing the analysis of CRs in the four situations (Table 6-9), it is found that participants would like to show more agreement with familiar interlocutors when responding to the compliments on appearance, character and ability. On the contrary, Malaysian Chinese, in facing of praise on personal belongings, preferred to keep accordance with unfamiliar speakers. On the other hand, only three participants out of 30 had performed Rejection in which the expressions are direct disagreements. This small amount of disagreements indicates that Malaysian Chinese undergraduates did not regularly violate the Accordance Maxim in order to show politeness and improve harmonious interaction with the interlocutors. In details, two disagreements were found in situation $4 \mathrm{~b}$ while another one appeared in situation 1b, therefore, if giving disagreements, Malaysian Chinese 


\section{POLITENESS IN COMPLIMENT RESPONSES OF MALAYSIA CHINESE UNDERGRADUATES}

undergraduates tended to disagree with familiar speakers on the topic of possessions.

\section{The Virtues-Words-Deeds Maxim}

$\mathrm{Gu}$ (1992) stated that speech and virtue are important elements in Confucian School which is the dominant idea in the daily communication of Chinese. Through analysis of the contents of this maxim, Returning (e.g., I think you have a very nice hair-cut), Offering (e.g., Do you want to have a look?) and Credit-shifting (e.g., It's bought (...) my (...) father (...)Oh this is my present from my father) have been identified as strategies that meet the Virtues-Words-Deeds Maxim. In responding to the compliments, it hardly revealed the contents of minimizing cost of the complimenters since there would not be any expenditures in time or substance, so all the politeness strategies used in the study were to maximize benefit to others.

As shown in Table 5, there are $64(15.8 \%)$ tokens of CRs in the study showing the Virtues-Words-Deeds Maxim, in which the Credit-shifting has been employed most by 34 tokens (53\%), followed by Returning (39\%) and Offering (8\%). Credit-shifting and Returning were mainly used to maximize the benefit to the interlocutors or in a few cases to family members. However, Offering which was mainly occurring for CRs on possessions shows that both maximizing benefit to others while cost to self by showing the smart phone to the interlocutors. Therefore, Malaysian Chinese undergraduates preferred to enhance the benefit to others while frequently violated the rule of maximizing the cost to self in their CRs.

As shown in Table 6-9, in situation 1 on appearance, 15\% strategies are Returning which is the only one that reflects the Virtues-Words-Deeds Maxim. Comparing situation 1a and 1b, participants returned more compliments $(21.8 \%)$ to unfamiliar friends in situation $1 \mathrm{~b}$ but less to familiar lecturer in 1a $(8 \%)$. When it comes to compliments on character in situation 2, participants applied more Virtues-Words-Deeds Maxim (35.9\%), particularly, 57.8\% in situation 2a, while $13.7 \%$ in situation 2b. Moreover, participants did not obey the Virtues-Words-Deeds Maxim much when they have got praises because of their great achievements in situation 3, only $12.1 \%$ of total with $4.5 \%$ in situation $3 \mathrm{a}$ and $19.2 \%$ in situation $3 \mathrm{~b}$. Be similar with situation 3 , only $4.5 \%$ of strategies revealing the Virtue-Words-Deeds Maxim in situation 4 on possession, in which $5.4 \%$ in situation $4 \mathrm{a}$ and $3.6 \%$ in situation 4b. As a conclusion, Malaysian Chinese participants would like to show their politeness through the Virtues-Words-Deeds Maxim in responding to compliments on character, especially tended to maximize the benefit to unfamiliar interlocutors with higher social status when they were complimented due to their great help.

\section{Discussions}

According to the analysis of the data collected through the questionnaires, it can be concluded that Malaysian Chinese undergraduates generally felt happy and appreciated to compliments and rarely regarded compliments as face-threatening acts. This finding is in tandem with Tang \& Zhang's (2009) finding of Mandarin Chinese who viewed compliments more as positive speech acts than FTAs.

Malaysian Chinese participants were more prone to accepting the compliments hence the Accordance Maxim was their primary consideration (see Figure 1). This finding is in contrast with Chen's (1993) study that mainland Chinese attached least value to Agreement Maxim of Leech (1983) when responding to compliments. Moreover, it is in line with recent study of Chen (2003) that the 


\section{POLITENESS IN COMPLIMENT RESPONSES OF MALAYSIA CHINESE UNDERGRADUATES}

Taiwanese are more governed by Agreement Maxim of Leech (1983) in CRs. Previous studies on CRs demonstrated that a great use of more acceptances of compliments among Chinese is due to the assimilation of Western culture (Chen \& Yang, 2010; Lee, 2015; Yuan, 2002). In the Malaysian Chinese community, it could be Western assimilation due to the social media and business which has contributed to the development of English language and Western cultures. Furthermore, as Thevendiraraj (2006) stated that in the English-educated social environment, English has been the dominant teaching and learning language for Malaysian. Therefore, parts of Chinese culture in Malaysian Chinese community have been gradually assimilated by Western culture.

Figure 1: Politeness Maxims with CRs

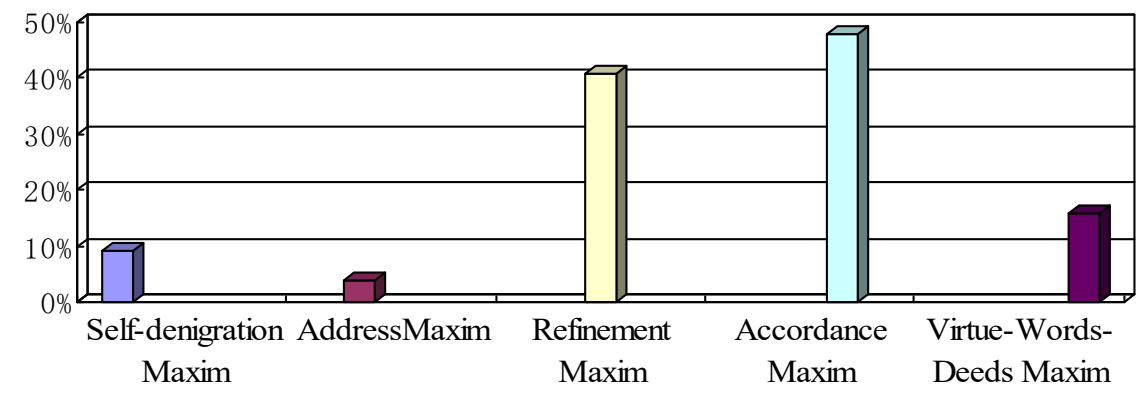

Malaysian Chinese undergraduates also kept much of the Refinement Maxim by applying a number of indirect speeches. This finding is in contrast with the statement that Malaysian Chinese are often regarded as being direct, upfront and straightforward in communication (Kuang, 2009; Phaveena, 2010). With reference to The Virtues-Words-Deeds Maxims, Malaysian Chinese undergraduates preferred to enhance the benefit to others. Especially, Malaysian Chinese participants would like to show their politeness through the Virtues-Words-Deeds Maxim in responding to compliments on character, especially tended to maximize the benefit to unfamiliar interlocutors with higher social status when they were complimented due to their great help.

Malaysian Chinese undergraduates did not attach much value on modesty in traditional Chinese culture as they were not prone to the Self-denigration Maxim. This finding differs from the traditional Chinese culture posed by Gu (1992) and Chen (1993) that the majority of the Chinese tend to belittle themselves and show modesty in order to respect others. Nevertheless, the later work of Chen \& Yang (2010) is consistent with the finding of the present study by saying that mainland Chinese tend to "given up" much of their modesty for the sake of agreeing with others when responding to compliments. Besides, Malaysian Chinese undergraduates favor elevating others rather than denigrating self. In sum, there is strong evidence that Malaysian Chinese undergraduates are more oriented towards the interactions that highlights a great relationship between 'the self' and 'the others' in social context while maintaining a stronger sense of the 'others' than the 'self'.

The Address Maxim was seldom kept as face-saving for Malaysian Chinese undergraduates. This finding shows distinction with Zhang's (2005) study that in the Chinese interpersonal communication, addressing one another is very common in all social interactions. However, the existing address terms with familiar lecturers by calling their professional terms, namely, unitary addressing, illustrates that Malaysian Chinese undergraduates overlook the address but tend to show a stronger sense of social order in the academic circle with familiar interlocutors.

With compliments on appearance, possession and especially ability, the Accordance Maxim has been 


\section{POLITENESS IN COMPLIMENT RESPONSES OF MALAYSIA CHINESE UNDERGRADUATES}

kept most among the five politeness principles. In terms of compliments on character, the participants were prone to the Refinement Maxim. Malaysian Chinese undergraduates would like to employ more diverse politeness strategies to reduce face-threatening acts with unfamiliar interlocutors in responding to compliments.

\section{Conclusion}

The analysis was viewed in the light of Gu's (1992) Politeness Principles, set against the cultural background of the Malaysian Chinese in this study, to investigate the application or violation of politeness strategies of Malaysian Chinese respondents with respect to CRs. On the whole, Malaysian Chinese undergraduates do not regard compliments as face-threatening acts. However, most of them attach great value on collectivism by saving other's face in communication. Malaysian Chinese undergraduates are generally governed by the Accordance Maxim, hence to be in agreement with the compliments, especially with familiar people by accepting the compliments thus to maintain their faces is regarded as a priority as well as to give prominence to the needs of the 'others'. Secondarily, Malaysian Chinese undergraduates are also likely to obey the Refinement Maxim in which indirect responses such as giggling/smiling are frequently used to show great politeness.

Nevertheless, the findings of the study justify that Malaysian Chinese undergraduates still stick to certain Chinese values such as face norm, interactive harmony, and senses of collectivism, which have been shown by their compliment responses. The researcher asserts that politeness in speech is still greatly valued by Malaysian Chinese undergraduates. Although, the preference of politeness strategies may vary between nowadays Malaysian Chinese and other Chinese circles and generations, there is still a link among them to some extent.

\section{References}

Barnlund, D. C., and Araki, S. (1985) Intercultural encounters: The management of compliments by Japanese and Americans. Journal of Cross-Cultural Psychology, 16 (1), 9-26.

Brown, P., \& Levinson, S. (1987). Politeness: Some universals in language usage. Cambridge: Cambridge University Press.

Chen, R. (1993). Responding to compliments: A contrastive study of politeness strategies between American English and Chinese speakers. Journal of pragmatics, 20 (1), 49-75.

Chen, S. H. (2003). Compliments responses strategies in Mandarin Chinese: Politeness phenomenon revised. Concentric: Studies in English Literature and Linguistics, 29 (2), 157-184.

Cheng, Y. (2009). A comparative study of compliment response strategies in American English and Chinese. Hu Nan University, Chang Sha, China.

Goffman, E. (1967). Interaction ritual: essays on face-to-face behavior. Anchor Books, New York.

Fraser, B. (1990). Perspectives on politeness. Journal of Pragmatics, 14, 219-236.

Gu, Y. G. (1990). Politeness phenomena in modern Chinese. Journal of Pragmatics, 14 (2), 237-57.

Gu, Y. G. (1992). Politeness, Pragmatics and Culture. Foreign language teaching and research, 1, 


\section{POLITENESS IN COMPLIMENT RESPONSES OF MALAYSIA CHINESE UNDERGRADUATES}

$10-17$.

Holmes, J. (1988). Paying compliments: a sex preferential positive politeness strategies. Journal of Pragmatics, 12 (3), 445-465.

Hu, H. C. (1944). The Chinese concept of 'face'. American Anthropologist, 46, 45-46.

Huang, D. (2012). A Constractive Study of Geoffrey Leech's and Gu Yueguo's Politeness Principles and Its Implications for Cross-cultural Communication. Si Chuan Normal University.

Leech, G. N. (1983). Principles of Pragmatics. London: Longman.

Liu, D. (1995). Sociocultural transfer and its effects on second language speakers' communication. International Journal of Intercultural Relations, 19 (2), 253-265.

Ruhi, S. (2006). Politeness in compliment responses: a perspective from naturally occurring exchanges in Turkish. Pragmatics, 16 (1), 43-101.

Sharifian, F. (2005). The Persian cultural schema of shekasteh-nafsi: a study of compliment responses in Persian and Anglo-Australian speakers. Pragmatics and Cognition, 13 (2), 337-361.

Spencer-Oatey, \& O., Ng, P. (2001). Reconsidering Chinese modesty: Hong Kong and Mainland Chinese evaluative judgments of compliment responses. Journal of Asian Pacific Communication, 11 (2), 181-201.

Thevendiraraj, P. (2006). Gender Variation in Compliment Responses: A Case of the Malaysian Tamil Community. University of Malaya.

Yu, M. C. (2003). On the universality of face: evidence from Chinese compliment response behaviour. Journal of Pragmatics, 35 (10-11), 1679-1710.

Zhang. X. Z. (2005). A comparative analysis of politeness strategies in Chinese and English. Shang Hai Normal University, Shang Hai, China.

\section{Contact Details of Authors:}

Ying-Qi WU (Wu, Y.Q.)

University of Malaya

600 Jln 17/12, Happy Gdn, 46400, Petaling Jaya, Selangor, Malaysia

Telephone: 011-27814288

E-mail: 956791312@qq.com

Dr. Baljit Kaur

Institution: retired staff of University of Malaya

149, Jalan Datuk Sulaiman 4, Taman Tun Dr. Ismail, 60000 Kuala Lumpur.

Telephone: 012-2356588 


\section{POLITENESS IN COMPLIMENT RESPONSES OF MALAYSIA CHINESE UNDERGRADUATES}

E-mail: $\underline{\text { krystalbal@hotmail.com }}$

\section{Biodata}

Yingqi Wu is currently a second year student in University of Malaya. He is pursuing Master of Linguistics. He holds a degree in English Study from Hei Bei Normal University for Nationalities. His interests include Pragmatics and Conversational Analysis in spoken and written contexts.

Dr. Baljit Kaur was a senior lecturer at the Faculty of Languages \& Linguistics in University of Malaya. She was with University of Malaya for 20 years before she retired in September 2016. Her research interests are in the field of Pragmatics and Discourse Analysis. 


\section{POLITENESS IN COMPLIMENT RESPONSES OF MALAYSIA CHINESE UNDERGRADUATES}

\section{APPENDIX A \\ ROLE PLAY SCENARIOS IN PRESENT STUDY}

Please read all the situations given.

Situation 1 Appearance (The outward or visible aspect of a person or thing)

Your familiar lecturer organized a party to celebrate the end of examination (task). You have dressed up for the party. As you arrive at the party,

Your lecturer says: "Dress nicely! You look so nice today!"

Your response:

Situation 2 Character (The combination of traits and qualities distinguishing the individual nature of a person or thing)

You meet your good friend in the hallway carrying some files. You help her (him) to take files to her (his) office.

She (he) says: "Wow! You like helping others. You are so kind and caring!"

Your response:

Situation 3 Ability (The qualities required to do something)

You have completed a presentation. After that your familiar lecturer gives you immediate feedback.

She (he) says: "Well done, your English is very good. And your presentation is well-organized. Thank you."

Your response:

Situation 4 Possession (Anything that is owned or possessed)

You have bought a new mobile phone. You visit your close friend's family. When you receive a call, your close friend notices that your phone is a new one. Having looked at it and tried some functions,

She (he) says: "Wow, how smart! It looks so nice. My phone doesn’t have such functions. It is really great!"

Your response: 


\section{POLITENESS IN COMPLIMENT RESPONSES OF MALAYSIA CHINESE UNDERGRADUATES}

\section{APPENDIX B QUESTIONNAIRE}

1. What is your instant response normally to a compliment?

2. Do you intentionally choose particular response strategies in particular situations?

3. What factors influenced your choices?

4. How do you feel when you receive compliments?

5. Is politeness shown when you respond to compliments? Is Chinese culture expected in your English speech? 